\title{
San Agustín y los sentidos espirituales: el caso de la visión interior
}

\author{
Fernando Martin-De Blassi \\ FACULTAD DE FILOSOFÍA Y LETRAS \\ UNIVERSIDAD NACIONAL DE CUYO \\ martindeblassi@hotmail.com
}

Resumen: Discurriendo en torno a la visión de Dios, Agustín de Hipona afirma en la Epistola 147 que los ojos interiores son jueces de los exteriores (Cum ergo interiores oculi iudices sivi oculorum exteriorum, 17, 41), pues los interiores ven muchas cosas que los exteriores no ven y las percepciones corporales, por su parte, no se juzgan con ojos carnales sino con aquellos del corazón (oculis cordis). El tema particular de esta disquisición es planteado igualmente en las Ep. 92 y 148 y también en el libro XXII (cp. 29) de La ciudad de Dios. Sobre la base de este tratamiento, el presente trabajo estriba en dilucidar las notas significativas que el Obispo de Hipona desarrolla a propósito de la visión interior y de su superioridad con respecto a la visión corpórea. Para la interpretación de los textos, se acude al apoyo instrumental de fuentes, junto con sus correspondientes versiones en lenguas modernas.

Palabras clave: Agustín de Hipona, sentidos espirituales, visión externa, visión interna.

Abstract: In the context of a consideration on the God's vision, Augustine of Hippo states in Epistle 147 that the inner eyes are judges of the exterior ones (Cum ergo interior oculi iudices sivi oculorum exteriorum, 17, 41), because the inner eyes see many things that the others do not see, and the corporal perceptions are not judged by carnal eyes. On the contrary, they are judged by the eyes of the heart (oculis cordis). The subject of this disquisition is also raised in Ep. 92, Ep. 148, and Book XXII (ch. 29) of The City of God. Consequently, the present work aims to elucidate the significant notes that St. Augustine develops regarding the inner vision and its superiority with respect to corporeal vision. For the interpretation of the texts, we refer to the instrumental support of sources, along with their corresponding versions in modern languages. Keywords: Augustine of Hippo, spiritual senses, external vision, inner vision. 


\section{A MODO DE PRESENTACIÓN}

Dentro de la historia del pensamiento cristiano y, en particular, del período patrístico, la tradición de los sentidos espirituales comprende varias facetas teóricas con sus respectivas fuentes filosóficas ${ }^{1}$. El tópico de marras no se trata de una metáfora a secas sino que se entiende, antes bien, como una activación del cuerpo sutil de la preexistencia, mediador entre el alma pura y el cuerpo sensible, grávido y pasajero ${ }^{2}$. J. Daniélou afirma que "los sentidos espirituales representan el florecimiento de la vida de la gracia que permite gustar, tocar y contemplar las cosas divinas" 3 . De modo que esta realidad apunta a dilucidar el estado al que llegará el alma cuando haya logrado unirse definitivamente con lo divino. La doctrina en cuestión reúne a su vez una lista significativa de representantes, configurada en particular por algunos paladines de la experiencia mística ${ }^{4}$. En relación con los escritores místicos, conviene señalar que no es posible establecer una dicotomía entre su enseñanza y la experiencia que proponen. Ya en la vida terrena — dicen- es posible vislumbrar algo del estado futuro del alma, a partir del desarrollo progresivo de los cinco sentidos espirituales 5 .

El fundamento de este saber descansa sobre la base de la ley conocida como de homonimia, que atribuye al hombre interior predicados análogos a los del hombre exterior ${ }^{6}$. Esta ley explota las virtualidades contenidas en el principio de que "lo semejante se conoce por lo seme-

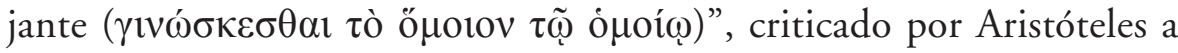
propósito de las gnoseologías de cuño materialista o semimaterialista ${ }^{7}$, pero asumido cuantiosamente por las noéticas agustiniana y tomasiana,

1 Cf. P. Gabrilyuk - S. Coakley (eds.), The spiritual senses. Perceiving God in Western Christianity (Cambridge University Press, 2012) 20-35, 56-70.

2 Cf. F. García BazÁn, El cuerpo astral (Obelisco, Barcelona 1993).

3 J. Daniélou, Orígenes (Ed. Sudamericana, Buenos Aires 1958) 375.

4 Existen, por cierto, autores sapienciales procedentes de otras ramas de espiritualidad no cristiana; cf. R. Ullman- J. Reichenberg (eds.), Misticos, maestros y sabios. Relatos de iluminación (Kairós, Barcelona 2009).

5 H. Crouzel, Origène et la "connaissance mystique" (Desclée de Brouwer, Paris 1961) 11.

6 Conforme con la tesis platónica de la superioridad del alma respecto del cuerpo (Timaeus 34c 3-4), Plotino afirma expresamente que "la casa del hombre es

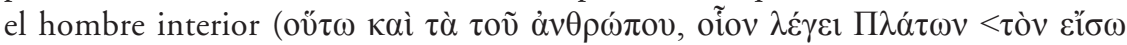
öv $\theta \rho \omega \pi \mathrm{ov}>, \mathrm{V} 1,10,9-10)$ ".

7 Cf. W. D. Ross (ed.), Aristotelis de anima (Clarendon Press, Oxford 1961) 405b 15,409 b 25 ss., 427 a 16 ss. 
en la medida en que el conocimiento significa poseer una semejanza $\left(\right.$ similitudo $^{8}$.

Frente a los hitos que jalonan la tradición a la cual me estoy refiriendo, puede afirmarse que Orígenes "representa, junto con San Agustín, la culminación del genio en el cristianismo antiguo", puesto que imprime decisivamente un giro irreversible en la historia de la espiritualidad, al fundar la teología en la ciencia bíblica ${ }^{10}$. De allí en más, hacer teología significará explicar y comprender sistemáticamente el mensaje de la Escritura para progresar en el conocimiento de los misterios divinos. Esta suerte de simbiosis propone pasar de la letra al espíritu del texto sagrado $^{11}$. De modo tal que, a partir de Orígenes, la comprensión profunda de Dios no estará separada de la experiencia espiritual que ello implica. Este camino reposa sobre dos niveles de sentido dentro de la Escritura, no yuxtapuestos ni mucho menos contradictorios, sino complementarios entre sí e, incluso, dispuestos de acuerdo con una gradación jerárquica: el nivel literal, de suyo imperfecto, y el espiritual o alegórico, que es mucho más verdadero. Es claro que subyace a esta modalidad la distinción platónica entre la realidad del mundo sensible y el inteligible ${ }^{12}$.

Cierto es que la aplicación del método alegórico no constituye una novedad absoluta, pues había sido implementado previamente por pensadores griegos, al escudriñar verdades profundas en los poemas homéricos y en la mitología antigua ${ }^{13}$. Filón de Alejandría desarrolla este

8 Cf. I. M. Anchepe, "Ni lo mismo ni lo otro. Sobre conocimiento y semejanza en la noética de Tomás de Aquino. Antecedentes agustinianos, debates actuales", en Scripta Mediaevalia 7/2 (2014) 113-136.

9 Cf. J. Daniélou, Orígenes... , introd.; asimismo, E. Prinzivalli, Magister ecclesiae. Il dibattito su Origene fra III e IV secolo (coll. "Studia Ephemeridis Augustinianum", 82; Instituto Patristico Augustinianum, Roma 2002).

10 La expresión de "giro irreversible" corresponde a Benedicto XVI, Los Padres de la Iglesia (Ágape Libros, Buenos Aires 2009) 37 ss.

11 Cf. H. De Lubac, Exégèse médiévale : les quatre sens de l'Écriture (Montaigne, Aubier 1959-1964).

12 Cf. P. A. Ciner, "Teología y experiencia mística en Orígenes: ¿̨una cuestión mal planteada?", en Scripta Mediaevalia 1 (2008) 71-90; “El legado de Orígenes a la teología cristiana contemporánea”, en La libertad del espiritu. Tres figuras en diálogo interdisciplinario: Teresa de Avila, Paul Ricoeur y Hans von Balthasar (Ágape Libros, Buenos Aires 2014).

13 Cf. A. Galindo Esparza, El tema de Circe en la tradición literaria: de la épica griega a la literatura española (Ed. de la Univ. de Murcia 2015) 121 ss. 
procedimiento en su lectura de los textos sagrados y existía ya una tradición alegórica en el mismo cristianismo primitivo, que leía el antiguo testamento en permanente alusión al nuevo, como una prefiguración de tal acontecimiento. Sin embargo, Orígenes es el primero en aplicar de forma metódica este tipo de exégesis, cuya legitimidad radica en la condición defectuosa de la letra. Muchos pasajes de la Escritura contienen, por cierto, elementos difíciles de interpretar si se los toma en sentido literal y requieren de otra clase de análisis para descubrir en ellos su significado ${ }^{14}$.

El núcleo inspirador de la obra literaria de Orígenes consiste en la triple lectura que hace de la Biblia. La interpretación consta de tres etapas no siempre sucesivas: la literal, la moral y la espiritual ${ }^{15}$, correspondientes a la tripartición establecida por la antropología a la sazón vigente en cuerpo, alma y espíritu ${ }^{16}$. Así las cosas, si se atiende a la mentada concordancia, la dimensión espiritual de la Escritura reclama el entendimiento de seres que hayan superado el peldaño puramente sensible y la sola vía ascética. Es aquí donde puede apreciarse con mayor nitidez el correlato práctico que exige el estudio teológico. Si uno no se vuelve espíritu, no podrá comprender el sentido último y verdadero contenido en las palabras de la Escritura. O bien, dicho a la inversa, es imposible colegir con una mirada puramente sensible el significado recóndito que encierra el texto sagrado; por mucho que alguien se esfuerce, si no se ha purificado del apego a lo sensible, no comprenderá.

Para Orígenes, la culminación de este ascenso está sintetizada en la categoría de los perfectos ( $\tau \dot{\varepsilon} \lambda \varepsilon 10 \imath$ ), quienes han recibido al $\lambda o ́ \gamma o \varsigma$ divino, antes o después del advenimiento de Cristo ${ }^{17}$. La diversidad del mensaje bíblico es concebida de manera unitaria en virtud de su contenido cristológico porque, si bien los profetas desconocieron al Cristo encarnado, ellos captaron en cambio la presencia inteligible del $\lambda$ ó $\gamma o \varsigma$ divino y su consecuente identificación con la mente de Cristo. Orígenes

14 Cf. C. Moreschini - E. Norelli, Patrología. Manual de literatura cristiana antigua griega y latina (Ed. Sígueme, Salamanca 2009) 145-162.

15 Cf. Orígenes, Hom. Num. IX, 7.

16 Cf. G. Mura (ed.), La teologia dei Patri (Città nuova, Roma 1981) vol. I, 208215, en part. n. 8: "L'uomo nella sua totalità è formato di corpo, anima e Spirito", 213-214.

17 Cf. C. Blanc (ed.), Origène. Commentaire sur Saint Jean (Cerf, Paris 1992) I 7 (9) (IV 11, 26-12,1). 
insiste en el hecho de que solo los perfectos poseen los sentidos espirituales agudizados mediante el ejercicio del discernimiento, por haber purificado hasta el extremo los ojos del entendimiento, destinados por naturaleza a distinguir la verdad y a contemplarla directamente en su interior ${ }^{18}$.

Por tales motivos, el ejercicio de los sentidos espirituales no representa una mística de índole puramente intelectual, pues el camino del ascenso del alma culmina en una transformación para la vida bienaventurada $^{19}$. La fecundidad de esta doctrina radica en el hecho de que el camino privilegiado para conocer a Dios encuentra en el amor su fuente y cumplimiento ${ }^{20}$. En un pasaje por demás expresivo, en virtud de las evocaciones que suscita, Agustín de Hipona justiprecia el primado del amor en el desenvolvimiento de los sentidos espirituales. Dios mismo, objeto supremo del querer, se torna susceptible de ser percibido por el hombre interior en el marco de una experiencia profundamente intuitiva, bien que a una unión como esta le corresponde una intensidad tan sólida que lo captado en ella no se encuentra afectado por las categorías propias de la dimensión espacio-temporal, es decir, de la extensión y la sucesión. Dice:

"Y sin embargo amo una especie de luz, de voz, y de fragancia y de alimento y de caricia, cuando amo a mi Dios, que es luz, voz, fragancia, alimento y caricia del hombre mío interior, donde resplandece a mi alma lo que el espacio no contiene; resuena lo que no arrebata consigo el tiempo; exhala sus perfumes lo que no se lleva el viento; saborea lo que no se consume comiendo, y donde la unión es tan firme que no la disuelve el hastío. Esto es lo que amo cuando amo a mi Dios"21.

18 Cf. Orígenes, Com. Cant. I, 4, 16.

19 Cf. L. Corso, "Teleología y virtud desde la perspectiva agustiniana del L. XIX del De civitate Dei”, en Diadokhé 1 (1998) 95-109.

20 Cf. Agustín de Hipona, Conf. X, 27; De moribus I, 15, 25.

21 A. Custodio Vega (ed.), Obras de San Agustín II: Las confesiones (BAC, Madrid $\left.{ }^{5} 1968\right) \mathrm{X}, 6$, 8: "Et tamen amo quamdam lucem et quamdam vocem et quemdam odorem et quemdam cibum et quemdam amplexum, cum amo Deum meum, lucem, vocem, odorem, cibum, amplexum interioris hominis mei, ubi fulget animae meae, quod non capit locus, et ubi sonat, quod non rapit tempus, et ubi olet, quod non spargit flatus, et ubi sapit, quod non minuit edacitas, et ubi haeret, quod non divellit satietas. Hoc est quod amo, cum Deum meum amo.” 
En sintonía con esta peculiar hermenéutica teológica, que conjuga en sí misma el arte de la exégesis con una singular concepción antropológica y la experiencia de los fenómenos anímicos supremos ${ }^{22}$, el Hiponense afirma en la Epistola $147^{23}$ que los ojos interiores son jueces de los exteriores, pues los interiores ven muchas cosas que los exteriores no ven y las percepciones corporales, por su parte, no se juzgan con ojos carnales sino con aquellos del corazón ${ }^{24}$. El tema particular de esta disquisición es planteado igualmente en las Ep. 92, 148 y también en el último libro de De civitate Dei (en lo sucesivo: $D c D)^{25}$, en referencia al problema de la visión beatífica. Sobre la base de este tratamiento, el presente trabajo busca dilucidar las notas significativas que Agustín de Hipona desarrolla a propósito de la visión interior y de su superioridad con respecto a la visión corpórea. En vista de tales propósitos, se reproduce en primer lugar la problemática sobre la visión beatífica que Agustín planeta en el pasaje señalado de $D c D$. Se enfatiza luego la importancia cognitiva que revisten los ojos espirituales, acudiendo de manera específica a las Ep. 92, 147 y 148 para dilucidar ese principio. Como tercer punto, se muestra que tal condición de excelencia reposa sobre una idea concreta de hombre, cuya plenitud radica en actualizar la mirada del alma. Se recupera seguidamente el tratamiento de Tomás de Aquino sobre el mentado asunto. Para finalizar, se puntualiza una serie de precisiones conclusivas, inferidas del análisis efectuado ${ }^{26}$.

Texto latino disponible en línea: http://www.augustinus.it. Se ha tenido igualmente a la vista la trad. de S. Magnavacca (ed.), Las Confesiones de san Agustín (Losada, Buenos Aires 2005) y el glosario de C. MaYer (ed.), Augustinus-Lexikon (Schwabe \& Co., Basel 1986-1994).

22 Cf. S. Magnavacca, "Los términos os-pectus-cor en Confesiones, VI”, en J. J. HerreRA (ed.), Fuentes del pensamiento medieval: continuidad y divergencias (Ed. UNSTA, San Miguel de Tucumán 2012) 301-314.

23 J.-P. Migne (ed.), Patrologiae Latinae Cursus Completus (Paris, 1841) 33, 596-622.

24 Cf. Fr. Lope Cilleruelo (ed.), Obras de San Agustín XI: Cartas (BAC, Madrid 1953), Ep. 147, 17, 41: "Cum ergo interiores oculi iudices sivi oculorum exteriorum, isti autem illis quodam officio nuntiandi et ministerio famulentur, multaque illi videant quae isti non vident, nihil isti videant, unde non illi tamquam praesides iudicent" (el subrayado es mío).

25 J.-P. Migne (ed.), Patrologiae Latinae..., 41, cp. 29.

26 A modo de intr. general, cf. E. Portalié, "Augustin (Saint)", en Vacant-MangeNOT, Dict. de théologie cath., t. I, col. 2268-2472; A. MAXSEIn, "Philosophia cordis bei Augustinus”, en Augustinus Magister (Paris 1954) vol. I, 357-371. 


\section{La CUESTión de La Visión BIENAVENTURADA EN DCD}

El último libro de $D c D$, que habla sobre el fin debido a la ciudad de $\operatorname{Dios}^{27}$, se enfrenta con el grave problema que concita la resurrección de los muertos. Por lo tanto, la reflexión acerca de la visión espiritual es desarrollada en el marco de tal aporía, al exponer cuál será la vida de los bienaventurados en sus cuerpos mortales y espirituales. La disputa de fondo radica en que ciertos filósofos niegan rotundamente la resurrección de la carne ${ }^{28}$. Nada obsta para suponer que la diatriba se dirija contra partidarios platónicos ${ }^{29}$. Agustín dedica buena parte de la discusión en refutar esa premisa ${ }^{30}$, demostrando que la resurrección del cuerpo no es contraria a la omnipotencia divina, dado que "la vetustez del cuerpo animal se trocará en la novedad del cuerpo espiritual" ${ }^{11}$. Dice que, si bien en esta vida el hombre es espiritual a pesar de su cuerpo, en el porvenir será espiritual incluso por su cuerpo, cuando la misma carne haya resucitado ${ }^{32}$.

Ahora bien, ante la cuestión relativa al cuerpo incorruptible de que gozarán los bienaventurados, Agustín interroga cómo podrá verse a Dios mediante ese cuerpo siendo que Él es puro espíritu. Comienza su disertación aclarando que ignora la índole del reposo eterno, porque supera la experiencia de los sentidos corpóreos. Como los santos habrán de vivir en una paz que está por encima de todo razonamiento creado - el humano y el angélico, no así el divino-, cualquier discurrir de nuestra inteligencia sería tan solo una imagen de aquella realidad inefable. Siendo partícipes de su paz, según su capacidad, la conocen los ángeles; los hombres, empero, por aguda inteligencia que posean, participan de ella en una medida muy inferior. Dice que los ángeles ven a Dios cara a cara, no de modo alternado, un momento sí y otro no, sino siempre. Y así como lo están viendo ellos ahora, también los verán los bienaventu-

27 Cf. DcD XXII, 1, 1: "[...] iste huius totius operis ultimus disputationem de civitatis Dei aeterna beatitudine continebit".

28 Cf. DcDXXII, 4: "Sed videlicet homines docti atque sapientes contra vim tantae auctoritatis [...] acute sibi argumentari videntur adversus corporum resurrectionem".

29 Cf. $D c D$ XXII, 28: "Quapropter Plato et Porphyrius, vel potius quicumque illos diligunt et adhuc vivunt".

30 Cf. $D c D$ XXII, 5-20.

31 Cf. $D c D$ XXII, 21: "[...] quod in sepulcris remansit, in spiritalis corporis novitatem ex animalis corporis vetustate mutatum resurget".

32 Cf. DcD XXII, 21. 
rados, no al presente en esta vida mortal, sino en el porvenir ${ }^{33}$. Por este mismo motivo, ante la inquietud de cómo será el desenvolvimiento del cuerpo espiritual, el Hiponense responde a partir de opiniones que se creen y no que se palpan mediante los sentidos sensibles ${ }^{34}$. Acude particularmente a fuentes escriturarias con el objeto de encontrar, mediante el despliegue del discurso racional, lo que ellas enseñan; puesto que, si bien las verdades de la fe son de naturaleza indemostrable, puede probarse en cambio la conveniencia y legitimidad de su asentimiento.

Pone el ejemplo del Profeta Eliseo, quien estando ausente en su cuerpo pero presente en su espíritu, vio a su criado Guejazí recibir a todas luces los regalos del sirio Naamán, a quien el Profeta había curado de la lepra ${ }^{35}$. Si Eliseo no necesitó de ojos carnales para ver lo que vio en su espíritu, ¿tendrán, entonces, los bienaventurados necesidad de ojos corpóreos? Cita también la Epistola I de Juan ${ }^{36}$, en cuyas líneas se lee que cuando Dios se manifieste, seremos semejantes a Él porque lo veremos tal cual es. Agustín aclara que por "cara de Dios" debe entenderse su manifestación y no una parte suya, como si Dios tuviese un rostro material $^{37}$. Por otra parte, acude a un pasaje de la Epistola primera a los Corintios $^{38}$, a fin de representar la diferencia existente entre la vida presente que se apoya en la fe y la futura, donde sí habrá una visión más clara.

La cuestión estriba en averiguar si Dios será visto también por ojos corpóreos, o no. En efecto, la fe reside en el corazón, no en el cuerpo, porque versa sobre lo que aún no se ve. La faz interior del hombre podrá ver en espíritu y sin interrupción pero, de nuevo, como se trata de un asunto no experimentado, no puede responderse a ciencia cierta hasta dónde alcanza el potencial del cuerpo espiritual en su relación con $\operatorname{Dios}^{39}$. Él podría espiritualizarlo y hacerlo capaz de una visión que no corresponda a ojos naturales; si bien la invisibilidad trascendente de Dios arredra el otorgarles semejante beneficio, solo reservado a los espíritus puros. La penetración que tengan los bienaventurados les permitirá ver incluso lo incorpóreo, pues a Dios se le ha de ver con los ojos del

\footnotetext{
Cf. DcD XXII, 29, 1.

Cf. $D c D$ XXII, 29, 2: "non dico quod iam video, sed dico quod credo".

2 Rey. 5, 8-27.

1 Jn. 3, 2.

Cf. DcD XXII, 29, 1: "Facies autem Dei manifestatio eius intellegenda est".

1 Cor. 13, 11-12.

39 Cf. $D c D$ XXII, 29, 3.
} 
corazón, iluminados y purificados. De allí que el premio reservado a la fe estribe en una visión diáfana, sin velos ${ }^{40}$.

Basándose en la Revelación, interpreta que cuando venga lo perfecto ${ }^{41}$, el cuerpo ya no agobiará el alma ni tampoco por su incorruptibilidad la obstaculizará en nada. Por tanto, los ojos corporales tendrán su cometido y estarán en su lugar, bien que sometidos enteramente al cuerpo espiritual y no a la determinación de objetos materiales como los percibidos sensiblemente en esta vida mortal ${ }^{42}$. Aun cuando ciertos animales gocen de visión aguda, tomando por caso las águilas, tales seres no ven sino cuerpos. En este sentido, los ojos espirituales deberán tener un potencial superior al de los ojos sensibles en virtud de la naturaleza incorpórea de Dios, que no está contenida en un lugar, sino toda entera en todas partes. No alternativamente, en el cielo o en la tierra, sino a la vez en lo uno y en lo otro. Esto no lo puede aprehender criatura alguna ${ }^{43}$.

El punto quinto de este locus parece contener una impronta filosófica mucho más acentuada que el resto. Dice que Dios conoce todo lo corporal y sin embargo no tiene cuerpo. Cada uno percibe la propia vida que vive ahora en el cuerpo y vivifica los miembros terrenos. Sin embargo, la vida de los otros, al ser de suyo invisible, se aprehende a través del cuerpo porque se sabe que un cuerpo está vivo y que realiza determinadas operaciones cuando se ve su movimiento. La percepción puede distinguir entre vivientes y no vivientes porque aprehende cuerpos con vida, no pudiéndolos ver sino a través del órgano sensible. En cambio, la vida sin cuerpo no puede ser captada por meros ojos corpóreos ${ }^{44}$.

De esta manera, así como los cuerpos vivientes pueden ser vistos por medio de ojos corporales, no es desacertado plantear que Dios pueda ser contemplado en el cielo por medio de los cuerpos espirituales, en la medida en que Él está presente en todas partes y gobierna todo lo corporal. En este sentido, Dios no será ya conocido y amado por la fe (que ve como en enigma y a través de un espejo) sino por una evidencia clarísima. El Hiponense sostiene que esto sucede también con los seres humanos, cuando expresan con la ayuda de sus cuerpos que están vivos:

40 Conviene tener presente que, en sus Retractaciones (I, 4, 1), Agustín corrige su opinión acerca de que los limpios de corazón serán los únicos en conocer la verdad.

41 Cor. 13, 9-10.

42 Cf. DcD XXII, 29, 2: "Habebunt tamen etiam illi oculi corporei officium suum et in loco suo erunt, uteturque illis spiritus per spiritale corpus".

43 Cf. DcD XXII, 29, 3.

44 Cf. DcD XXII, 29, 5. 
tan pronto como uno los mira, no cree que viven sino que lo sabe, pues no se puede ver la vida sola sin los cuerpos que ella anima. De la misma manera, adondequiera se dirija la mirada espiritual en la visión bienaventurada, podrá verse a Dios rigiendo todas las $\operatorname{cosas}^{45}$.

De tal suerte se concluye este capítulo que cabe la inferencia de dos presuntos corolarios, a saber, o bien aquellos ojos tendrán una cualidad semejante a la de la mente, para ver a Dios y poder ver asimismo las naturalezas incorpóreas, o bien se conocerá a Dios tan claramente que será visto en espíritu no solo por cada uno, sino también en los demás, en sí mismo, en el cielo nuevo y en la tierra nueva, y de igual modo en toda criatura entonces existente. También será visto presente en todo cuerpo con los ojos del cuerpo, a cualquier punto donde sean dirigidos los ojos del cuerpo espiritual ${ }^{46}$. La solución más recomendable desde la óptica agustiniana debería de ser que, en el cielo y en la tierra nuevos, habrá una presencia tan manifiesta y gloriosa de Dios que hasta los ojos corporales la percibirán y gozarán de ella. Sería empero una visión indirecta, de reflejo de la gloria divina en las criaturas tanto celestes como terrestres ${ }^{47}$.

\section{El tema de los ojos espirituales en LAS eP. 92, 147 y 148}

a) La diferencia entre el percibir exterior y el distinguir interior

En cuanto a la Ep. 147, acerca de si Dios podrá ser visto por ojos corporales, y en relación con el tema de este trabajo, pueden enunciarse las siguientes ideas. Una vez más, el interrogante de fondo gira en torno al cuerpo incorruptible de que gozarán los bienaventurados. Agustín de Hipona pregunta si Dios podrá ser visto mediante aquel cuerpo puesto que Él es puro espíritu ${ }^{48}$. Tal como se ha venido mencionando a propósito de la condición inseparable que tiene la propia vivencia espiritual respecto del conocimiento divino, comienza su disertación recalcando el matiz experimental que debe asumir la investigación en cuestión, pues

45 Cf. DcD XXII, 29, 6.

46 Cf. DcD XXII, 29, 6: "Aut ergo sic per illos oculos videbitur Deus, ut aliquid habeant in tanta excellentia menti simile [...] aut, quod est ad intellegendum facilius, ita Deus nobis erit notus atque conspicuus".

47 Cf. DcD XXII, 29, 2.

48 Cf. Ep. 147, 1, 1; DcD XXII, 29, 3. 
aconseja atender más al modo de vivir que al de hablar ${ }^{49}$. De acuerdo entonces con estos términos, aconseja percibir las palabras del intelecto según el hombre interior que se renueva de día en día, a diferencia del hombre exterior, siempre sujeto al devenir y al perecer ${ }^{50}$. En el hombre interior habita la fe y la garante de su experiencia es la verdad, que ilumina desde dentro para ver con mayor perfección ${ }^{51}$.

En uno de los apartados de la mencionada Epistola, el Hiponense propone realizar el siguiente itinerario: dice que se considere lo visto, lo creído, lo aún no sabido y que se advierta cómo han sido vistos tales objetos, si por acción del cuerpo o de la mente, y cómo han sido vistas las mismas representaciones que él califica de verdaderas, si recordando haberlas visto mediante los sentidos sensibles — como son percibidos los cuerpos- o si nunca han sido captadas por el ojo corporal, sino que han sido aprendidas por la mente y se ha llegado a concluir la prestancia de su certeza, así como cuando se ve la propia voluntad y su deseo de perseguir un determinado fin $^{52}$.

Luego de establecer estas diferencias, Agustín puntualiza que ora se vea con el cuerpo ora con la mente, la distinción entre ambas especies de visión se ve con la mente y no con el cuerpo. Lo visto por la mente no necesita de ningún órgano corporal para saber que eso es verdadero. Por el contrario, no sucede lo mismo con los objetos vistos por el cuerpo, porque si no hay una mente que reciba sus anuncios, aquellos no son susceptibles de ciencia. En efecto, la facultad que recibe tales noticias deja fuera los objetos materiales y encomienda a la memoria las imágenes forjadas a partir de la percepción de esos objetos en cuanto semejanzas incorpóreas de los cuerpos. Cuando quiera, podrá extraerlas del depósito de la fantasía y ofrecerlas a la mirada del entendimiento para juzgarlas. Ahora bien, en este proceso resulta evidente que el objeto corporal y su configuración quedan fuera, mientras que su imagen se contempla dentro. Aquel está ausente a la mente, mientras que esta se halla presente. Toda imagen es semejanza incorpórea de un cuerpo que se alberga en el depósito interior y se patentiza al propio espíritu

49 Cf. Ep. $147,1,1$

502 Cor. 4, 16.

51 Cf. Ep. 147, 1, 2: "[...] sed aut Scripturis canonicis credas, si quid nondum quam verum sit vides, aut interius demonstranti veritati, ut hoc plane videas".

52 Cf. Ep. 147, 16, 38. 
por acción de la memoria. Uno ve en su interior, sin necesidad de ojos sensibles y sin vacilar sobre la presencia de tales elementos. Aunque se los aprehenda de forma invisible, no se duda de su presencia ni mucho menos de que son vistos por el ojo espiritual ${ }^{53}$.

En relación con esta última observación, el Hiponense plantea la inquietud de si acaso los ojos corpóreos pueden compararse con los ojos del corazón, en la medida en que estos ejecutan un discernimiento a propósito de la veracidad y presencia de las representaciones interiores. Su respuesta manifiesta que ni siquiera se juzga los objetos sensibles con los ojos carnales, porque toda sentencia no puede sino ser efectuada por la mente. Decir algo a propósito de su bondad o maldad, de su grandeza o pequeñez, de la cercanía o lejanía espacial, conviene solamente a la mirada interior. De allí que los ojos interiores sean jueces de los exteriores. Estos últimos tienen la función de siervos con respecto a aquellos, pues les toca el ministerio de anunciar, mientras que a los otros de presidir en el orden del conocimiento. Los ojos interiores ven, por cierto, muchos pormenores que los exteriores no ven, y estos últimos no intuyen nada que no esté sujeto al juicio de los interiores. Distinguiendo lo interior de lo exterior, se antepone infaliblemente uno a lo otro, se abandona lo exterior fuera del propio ser y se permanece dentro con lo visto interiormente, juzgándolo luego mediante normas incorporales ${ }^{54}$.

\section{b) LA Fe TAMBIÉN TIENE OJOS}

Según lo dicho en el apartado anterior, Agustín señala la importancia de la fe para lograr una paulatina interioridad en la visión. Ahora bien, conviene entonces preguntarse por qué motivo la fe no solo anticipa la visión espiritual, sino que al mismo tiempo garantiza su cumplimiento $^{55}$. Este interrogante se vincula directamente con el doble orden de prelación que figura en el Sermón 43, 9: "intellege ut credas, crede ut intellegas" y podría responderse de múltiples formas, todas ellas igualmente legítimas. Respecto de la temática que se analiza en esta oportunidad, me parece más apropiado remarcar lo siguiente.

53 Cf. Ep. 147, 16, 38

54 Cf. la cita en n. 23.

55 Cf. L. Coenen y otros, "fe", en Diccionario Teológico del Nuevo Testamento (Sígueme, Salamanca $\left.{ }^{3} 1990\right)$ vol. II, 170 ss. 
La indagación agustiniana acerca del binomio fe-razón manifiesta un asunto capital porque atañe a las fuentes mismas del conocimiento humano $^{56}$. Es decir, obedece a una exigencia no tanto de la creencia cuanto de la verdad. En primer lugar, Agustín entiende por fe una adhesión firme de la inteligencia a la autoridad de otro ${ }^{57}$, en la medida en que se cumple con la palabra empeñada ${ }^{58}$. Este concepto bien pudo haberlo tomado de Cicerón ${ }^{59}$. La distinción entre fe y razón da pie a la que cabe entre creer y ver. Mientras el ver se ordena a algo actualmente presente (sensible o inteligible), el creer supone la declaración testimonial ${ }^{60}$. Asimismo, el acto de creer se realiza ante lo que no se puede ver, ni siquiera es dable acceder a su contenido por vía discursiva. No podría ser de otra manera, porque si no hubiese oscuridad, ya no habría un acto de fe sino de razón ${ }^{61}$.

Ello no obstante, la fe tiene su propia certeza ${ }^{62}$. Supone una especie de visión interior ${ }^{63}$, atestiguada por la propia conciencia ${ }^{64}$. No responde desde luego a la evidencia inteligible, pero tampoco el contenido de la fe es ajeno de suyo a la razón. Entendida como fuente de conocimiento, la fe admite la verdad fundada en la autoridad y se ordena al conocimiento de lo que es necesario para alcanzar la felicidad ${ }^{65}$. Cumple el cometido de una llamada admonitoria externa, que conduce hacia la luz de la verdad interior ${ }^{66}$. De allí que la fe también tenga ojos con cualidades superiores a los del cuerpo, por ser más grandes, potentes y perspicaces. No engañan a nadie y ven lo invisible ${ }^{67}$.

\footnotetext{
56 Cf. Contra academicos III, 20, 43; De ordine II, 9, 26; De moribus I, 2, 3.

57 Cf. De spiritu et littera 32, 54.

58 Cf. Sermo 49,2: "Fides appellata est ab eo quia fit quod dicitur".

59 Cf. De officiis I, 23: "[...] credamusque, quia fiat quod dictum est, apellatam fidem".

60 Cf. Ep. 147, 2, 7.

61 Cf. Conf. VI, 5, 7.

62 Cf. Sermo 305 A, 9: "Certe hoc fide retinemus".

63 Cf. De Trinitate I, 3: "videmus in nobis".

${ }^{64}$ Cf. De Trinitate XIII, 1, 3: "Tenet certissima scientia, clamatque conscientia".

${ }^{65}$ Cf. De Trinitate XIII, 7, 10: "Quidquid amabitur aderit [...] et summus Deus summum bonum erit".

66 Cf. De utilitate credendi XIV, 46.

${ }^{67}$ Cf. En. in ps. 145, 19: "Et unde, inquit, video quod non videtur? Omnino habet oculos fides; et maiores oculos, et potentiores et fortiores. Hi oculi neminem deceperunt".
} 
Para el creyente, aquello invisible es algo visible para Dios. Ambos actos coinciden en lo mismo. De modo tal que el creer implica no solo una propedéutica para ver con más claridad, sino también la exigencia propia de un conocimiento seguro, pues la fe es siempre principio de conocimiento $^{68}$. En efecto, como la ciencia no se perfecciona en este mundo sino en el futuro, el creyente debe creer lo que todavía no ve, esperando y amando la futura visión. Pero la fe no anula los ojos de la razón; más aún, los integra en provecho de la verdad. Aquella tiene su propio potencial y puede aprender de alguna manera la verdad que entraña eso mismo que todavía no ve ${ }^{69}$.

Por consiguiente, la fe ordena hacia una visión completa ${ }^{70}$. Tanto la luz de la razón como la de la fe son, cada una a su modo, necesarias para acceder a la verdad ${ }^{71}$. Sin fe, la razón no alcanza su máximo grado de aprovechamiento; sin razón, la fe no se adecua al curso natural del conocimiento humano. De esta manera, la autoridad exige fe y prepara al hombre para la razón ${ }^{72}$.

\section{c) El elemento necesario de la luz}

En la Ep. $148^{73}$, Agustín recalca que los ojos del cuerpo mortal no pueden ver en absoluto sino cuerpos separados por alguna distancia lo$\mathrm{cal}^{74}$. Ahora bien, las cosas invisibles no se ven sino con los ojos del corazón. El Obispo de Hipona opina que sin luz no pueden verse tales realidades, tan verdaderas, tan claras y tan ciertas. Invita a contemplar esa luz y observar si algún rayo de los ojos corporales puede acercarse a ella. Viendo esa luz, no hay espacios o intervalos locales, al modo como

68 Cf. De Trinitate IX, 1: "Certa enim fides utcumque inchoat cognitionem; cognitio vero certa non perficietur, nisi post hanc vitam, cum videbimus facie ad faciem".

69 Cf. Ep. 120, 2, 8: "Habet namque fides oculos suos, quibus quodammodo videt verum esse quod nondum videt, et quibus certissime videt, nondum se videre quod credit".

70 Cf. En. in ps. 138, 14: "Facta est mihi nox illuminatio".

71 Cf. De ordine II, 5, 16: "Duplex enim est uiam quam sequimur, cum rerum nos obscuritas movet, aut rationem, aut certe auctoritatem".

72 Cf. De Ordine II, 9, 26-27: "Auctoritas autem partim divina est, partim humana: sed vera, firma, summa ea est quæ divina nominatur".

73 J.-P. Migne (ed.), Patrologiae Latinae..., 33, 622-630.

74 Cf. Ep. 148, 1, 1: "Causam quippe adiunxi cur hoc dixerim, ne scilicet Deus ipse corporeus esse credatur, et in loci spatio intervalloque visibilis; nihil enim videre aliter istius corporis oculus potest". 
la imaginación suscita el recuerdo indistinto del cielo o de la tierra sin apelar por ello a su extensión ${ }^{75}$. La imagen retórica podría ser una reminiscencia de la estructura ocular descrita en el Timeo platónico ${ }^{76}$, que si bien Agustín no cita de modo expreso en este pasaje, se sabe que lo conoce a través de Cicerón y que acude a esa fuente en otros lugares de su $D c D$ con el propósito de refutar la opinión de Porfirio ${ }^{77}$, de cuño plotiniano $^{78}$, sobre la separación tajante entre alma y cuerpo como condición indispensable para alcanzar la felicidad definitiva ${ }^{79}$.

Continúa diciendo que las imágenes son una semejanza de cuerpos y no cuerpos propiamente dichos. Tales formas imaginarias no presentan cualidades corpóreas, están en el alma y no se hallan contenidas por límites locales. De modo tal que pueden instalarse en la memoria sin ocupar un determinado espacio ni estar separadas por intervalos, ni tampoco estar fuera del ojo del corazón porque él, en efecto, emite su rayo para verlas todas juntas ${ }^{80}$. Cada una de estas realidades están contenidas todas juntas en un mismo reservorio espiritual ${ }^{81}$. Se las conoce siempre que puedan ser contempladas por la mirada de la mente. Al contemplarlas, no se ha debido iluminar una magnitud discreta, ni se ha tenido que dirigir los ojos corporales hacia un punto externo. Tampoco el corazón, al ser persuadido de estas verdades, resulta herido por el sonido de una voz material, ni se requiere de brazos fuertes para asirlas ${ }^{82}$.

75 Cf. Ep. 147, 17, 42-43.

76 Cf. Platón, Timeo, ed. bilingüe de J. Zamora Calvo (Abada, Madrid 2010) 45 b-46 c.

77 Cf. Porfirio, Contra los cristianos, rec. de fr., trad., intr. y notas de E. A. RamosJurado y otros (Servicio de Publicaciones de la Univ. de Cádiz 2006) 5-27. Sobre las nociones porfirianas acerca del alma cf. A. Galindo Esparza, El tema de Circe... , 130-132.

78 Cf. En. I 2 y I 4, passim.

79 Cf. $D c D$ XIII, 16-17; XXII, 26; N. Cipriani, "El rechazo del pesimismo porfiriano en los primeros escritos de san Agustín”, en Augustinus 55/218-219 (2010) 277-307.

80 Cf. Conf. X, 8 ss.

81 Adviértase que Plotino describe de la misma manera el modo en que las realidades inteligibles se hallan contenidas en la Inteligencia, no separadas localmente como las del mundo sensible sino juntas (En. V 9, 9, 14-16; V 8, 9, 19-23; VI 6, 7, 1-7).

82 Cf. Ep. 147, 17, 44. 
Estas observaciones retoman algunas tesis argüidas en la Ep. $92^{83}$, donde Agustín asevera que la luz de la mente purificada será idónea para ver a Dios. Por el contrario, el órgano corporal separa al hombre de quien es inconmutable, por hallarse sujeto a la variación de magnitudes y a las propias limitaciones que impiden captar lo omnipresente. Suponiendo que el semblante divino fuese corpóreo, se seguiría el absurdo de que entre el rostro material de Dios y el órgano corporal habría un intervalo de espacio, así como también un límite que recorte las figuras. Es la semejanza, empero, que ha sido establecida en el hombre interior, la que permite ver a Dios. En este sentido, interpretando la sentencia paulina de 1 Cor. 13, 12, nuestro autor resume que Dios será visto mediante el mismo órgano con que se lo ve en esta vida mortal por medio de la $\mathrm{fe}^{84}$.

El hombre interior, imagen de Dios, habita ya en cierto sentido en esa luz a la que ninguna sensación de los ojos corporales tiene acceso y en cuyo ámbito las realidades contempladas con el ojo espiritual se distinguen entre sí, pero sin estar separadas por algún espacio local. Se antepone, por tanto, la luz del corazón que juzga a toda luz corpórea que es juzgada, no solo ya por un discernimiento de la razón, sino también por una apetencia del amor. Mientras más espiritual se vuelve el ser humano, menos animal es y puede juzgar cada ente, cada elemento que arriba a su percepción sensible mediante el ojo interno del corazón. De lo contrario, el hombre que vive en la estulticia juzga los temas espirituales como boberías ${ }^{85}$.

\section{LA PLENITUd DE LA VISIÓN ESPIRITUAL Y SU RECEPCIÓN EN TOMÁS DE AQUINO}

El planteamiento hasta aquí consignado tiene asidero en la concepción antropológica agustiniana, heredera en no pocos aspectos de la filosofía plotiniana ${ }^{86}$, aun cuando sea conveniente recordar los influjos peripatéticos y estoicos, propiciados en la literatura temprana de Agus-

\footnotetext{
J.-P. Migne (ed.), Patrologiae Latinae..., 33, 318-321.

Cf. Ep. 92, 1-4.

85 Cf. Ep. 147, 18, 45. Juicio análogo al de Plotino en torno a la debilidad en la contemplación, cf. En. III 8, 4, 31-46.

86 Cf. É. Gilson, La filosofía en la Edad Media, trad. de A. Pacios y S. Caballero (Gredos, Madrid 1976) 118-130; H.-I. Marrou, Saint Augustin et la fin de la culture antique (de Boccard, Paris 1938); Ch. BOYER, Christianisme et néoplatonisme dans la formation de saint Augustin (G . Beauchesne, París 1920).
} 
tín: De moribus, De ordine, De quantitate animae, De libero arbitrio ${ }^{87}$. El hombre es ante todo un alma que se sirve de un cuerpo y, en cierto sentido, lo trasciende jerárquicamente. Sin embargo, por mucha influencia que haya recibido del neoplatonismo, el pensamiento cosmológico de Agustín es optimista en relación con la naturaleza y el mundo. La materia ha sido creada y, por lo tanto, el alma no está destinada al cuerpo como un castigo que deba purgar, sino por ser causa de la organización viviente de la materia. Con todo, puede afirmarse que las relaciones entre alma y cuerpo no siempre son del todo armoniosas. El cuerpo no es en sí mismo prisión del alma, pero ha llegado a serlo como consecuencia del pecado original ${ }^{88}$. Dado que el alma ha sido creada para regir el cuerpo, debido al pecado resulta regida por él y constreñida al mundo material y sensible. El alma no debe liberarse del cuerpo, sino de su falta de reconocimiento como realidad espiritual. No se trata de negar los cuerpos tales como fueron provistos por la bondad divina a los primeros hombres, sino de ordenar lo que menoscabó la pena del pecado. La rebelión del cuerpo produce la concupiscencia y la ignorancia. La tranquilidad en el orden conlleva la paz ${ }^{89}$. Si el cuerpo experimenta desconcierto en su disposición natural, ello se debe a los efectos provocados por esa rebelión.

El alma está presente toda entera en el cuerpo todo entero, y se encuentra unida a él por la acción que ejerce para vivificarlo. Atenta a cuanto acontece en el cuerpo, nada le pasa inadvertido. Aun cuando los objetos exteriores entren en contacto con los órganos sensoriales, el alma no padece tales afecciones porque, siendo más importante que el cuerpo, no puede estar sujeta a las impresiones ejercidas por algo inferior a ella. Debido a la vigilancia de sus modificaciones corporales, el alma genera la sensación desde sí misma a partir de una imagen semejante al objeto; motivo por el cual las sensaciones son acciones que el alma ejecuta y no afecciones que padece. Inestabilidad y cambio son características de los objetos que rodean el cuerpo. Como estas condiciones reflejan una falta de permanencia y, por tanto, una carencia de ser, los objetos sensibles

87 Cf. Nello Cipriani, "El influjo de Varrón sobre el pensamiento antropológico y moral de los primeros escritos de san Agustín" y "El modelo antropológico en el libro I de las "Confesiones»", Augustinus LV, 218-219 (2010) 241-275, 385-400.

88 Cf. Conf. X, 30 ss.; DcD XIII, 14-15; De gratia et libero arbitrio IV, 7-9; De correptione et gratia XII, 38.

89 Cf. DcD XIX, 13, 1: "pax omnium rerum tranquillitas ordinis". 
no pueden ser captados con propiedad por el pensamiento; ni bien se intenta asirlos mediante una definición de lo que son, ya han mutado y se han vuelto otra cosa. En sentido estricto, conocer implica aprehender un objeto que no cambia y cuya estabilidad permite retenerlo bajo la mirada del espíritu. La verdad, entonces, constituye la captación o el descubrimiento interior de esta regla fija en cuanto realidad puramente inteligible y, por lo mismo, inmutable; en consecuencia, necesaria y eterna, porque solo es verdadero lo que verdaderamente existe. Incluso el propio pensamiento es de naturaleza contingente, puede fallar, y por ello mismo la necesidad con que la verdad se impone a la razón es signo de su trascendencia y, en última instancia, de su completa remisión a Dios. Siendo conocida por la razón, la verdad está por encima de la inteligencia ${ }^{90}$.

La temática descripta en los párrafos anteriores es abordada profusamente por Agustín en varios pasajes de su obra y desde diversas perspectivas. Casi podría decirse que constituye una especie de bajo continuo, sobre cuya base se suceden los múltiples acordes que componen la melodía de su pensamiento. En los Soliloquios, por ejemplo, el Hiponense dice que el conocimiento divino ofrece un deleite que no proporcionan las objetos sensibles, aunque ello se deba a la diversidad de su naturaleza y no a la diferencia entre las noticias de ambos objetos. En efecto, con la misma mirada se abraza tanto la tierra como la serenidad del cielo, aun cuando agrade más la vista de este que la de aquella. Y si no se engañan los ojos, a pesar de que la tierra no deleite tanto como el cielo, la certeza de su visión es análoga. Pues las cosas visibles de la tierra -que representan los axiomas de las diversas disciplinas- distan de las realidades divinas - es decir, de la majestad inteligible de Dios- como la visión de la tierra dista de la magnificencia del cielo ${ }^{91}$.

Por consiguiente, la razón muestra a Dios como el sol se muestra a los ojos, porque las potencias del alma son como los ojos de la mente. Los axiomas de las ciencias particulares se asemejan a los objetos ilustrados por el sol, a fin de que puedan ser vistos como se ve la tierra y todo lo terreno. Así como Platón, en la alegoría de la caverna, emplea la imagen

90 Cf. De magistro XI, 38; De vera religione XXXIX, 72: "Noli foras ire, en te ipsum redi; in interiore homine habitat veritas; et si tuam naturam mutabilem inveneris, trascende et te ipsum".

91 Cf. Soliloquiorum I, 5, 11. 
del sol por analogía con la idea del Bien, que es causa de todas las cosas rectas y bellas, engendradora de la luz en el ámbito visible y productora de la verdad en el inteligible ${ }^{92}$, también Agustín afirma de Dios que es como el sol que baña con su luz los objetos visibles, mientras que la razón es para la mente como el rayo de la mirada lo es para los ojos ${ }^{93}$. No es lo mismo tener ojos que mirar, ni tampoco mirar que ver. Es por ello que el alma necesita no solo tener ojos, sino también que requiere de las operaciones del mirar y del ver. La razón ejerce por sí misma la facultad consagrada a ser la mirada del alma (aspectus animae); sin embargo, no todo mirar (aspicere) implica siempre un ver (videre). Por este motivo, la mirada penetrante seguida de visión se llama virtud, es decir, una razón recta y perfecta ${ }^{94}$. El ojo del alma designa la mente purificada de toda mancha corporal, esto es, alejada y limpia del apetito de las cosas corruptibles. A la mirada sigue la visión misma de Dios, que es el fin de la mirada, no porque esta cese ya sino porque Dios es el único objeto a cuya posesión aspira. Tal es la verdadera y perfecta virtud, la razón que llega a su fin, premiada con la vida feliz. Y la visión es un acto intelectual que se verifica en el alma como resultado de la unión del entendimiento y del objeto conocido, del mismo modo que en la visión ocular concurren el sentido y el objeto visible, sin que pueda eliminarse alguno, so pena de anularla ${ }^{95}$.

En este mismo orden de ideas y desde otra posición histórica, Tomás de Aquino cita de momento la Ep. 147 del Hiponense y el cp. 29 del libro XXII de su $D c D$ para argumentar a favor de la superioridad de los ojos espirituales respecto de los ojos corporales. El Aquinate sostiene que la bienaventuranza perfecta consiste en la visión de la esencia divina, toda vez que la perfección del intelecto progresa cuando conoce la esencia de algo. En este sentido, como el intelecto puede conocer la esencia de algún efecto creado, su perfección no se hallará colmada hasta que

92 Cf. Respublica VII, 517 b-c.

93 Cabría pensar que estas imágenes responden o un caso de polifonía o bien de intertextualidad, en la medida en que el discurso agustiniano incorpora una diversidad de voces de ascendencia platónica, materializadas indirectamente por la propia pluma del Hiponense. Cf. H. Calsamiglia - A. Tusón, Las cosas del decir. Manual de análisis del discurso (Ed. Ariel, Barcelona 2001) 148 ss.

94 Cf. Soliloquiorum I, 6, 13: " $R$. Aspectus animae, ratio est: sed quia non sequitur ut omnis qui aspicit videat, aspectus rectus atque perfectus, id est quem visio sequitur, virtus vocatur; est enim virtus vel recta vel perfecta ratio".

95 Cf. Soliloquiorum I, 6, 12. 
no logre la unión con Dios por ser la causa última de semejante efecto ${ }^{96}$. Dice, a su vez, que es imposible ver la esencia divina con el sentido de la vista porque ninguna facultad de índole sensitiva puede trascender lo corpóreo en la medida en que el acto está proporcionado a su sujeto y, por tanto, la captación sensible es acto de un órgano corporal. Puesto que Dios es incorpóreo, se infiere que ni los sentidos corporales ni la la imaginación pueden ver a Dios, sino solamente el intelecto ${ }^{97}$. Los ojos glorificados del entendimiento verán a Dios como se aprehende la vida de alguien vivo, puesto que la vida en sí misma no se ve directamente con el ojo corporal sino tan solo de forma accidental, al ser percibida por otra facultad una vez que llega a los sentidos. Intentando resolver este dilema, Tomás de Aquino reproduce como base textual de su disertación los mismos argumentos que desarrolla Agustín de Hipona en su $D c D$ XXII, 29, y que han sido expuestos previamente en la sección "1" de este trabajo $^{98}$.

Tomás plantea, asimismo, el hecho de que el entendimiento creado no puede por su sola capacidad natural ver a Dios de modo directo, toda vez que lo conocido está en el que conoce según su modo de conocer y el conocer se ajusta a la naturaleza del cognoscente ${ }^{99}$. Puesto que el modo de ser del objeto divino excede la naturaleza humana, se sigue que su conocimiento estará por encima de sus capacidades ${ }^{100}$. De modo que el intelecto creado no puede por sí mismo ver a Dios a menos que este lo ilumine y se una a él haciéndose inteligible ${ }^{101}$. Agustín ya se había

96 Cf. S. Th. I-II, q. 3, a. 8, sol.: "Respondeo dicendum quod ultima et perfecta beatitudo non potest esse nisi in visione divinae essentiae". Texto latino disponible en línea: http://www.corpusthomisticum.org

97 Cf. S. Th. I, q. 12, a. 3, sol.: "Unde nec sensu nec imaginatione videri potest, sed solo intellectu".

98 Cf. S. Th. I, q. 12, a. 3, 2 et ad 2.

99 Cf. S. Th. I, q. 75, a. 5, sol. Tanto en el sistema plotiniano como en la tradición neoplatónica posterior, esta tesis cognitiva es planteada además en un sentido ontológico, a modo de principio que articula la procesión y diferencia fundamental entre las sucesivas hipóstasis cf. mi "Considerations on the concept of audacity (tólma) in Plotinus”, en International Philosophical Quarterly 57/225 (2017) 19-30.

100 Cf. G. CResta, “¿Es posible el conocimiento de Dios? - aproximaciones y diferencias entre Santo Tomás y San Buenaventura”, en línea: http://www.hottopos.com/ rih4/gerald.htm, fecha de consulta: 01.09.2017.

101 Cf. S. Th. I, q. 12, a. 5, sol.: "Et hoc augmentum virtutis intellectivae illuminationem intellectus vocamus; sicut et ipsum intelligibile vocatur lumen vel lux". 
inclinado a favor de esta misma tesis. Mutatis mutandis, en un pasaje del Sermón 117 (PL 38) puede leerse lo siguiente:

"[...] los ojos no pueden comprender o abarcar con su mirada los cuerpos que tienen ante ellos. Luego, ¿qué ojo del corazón comprende o abarca a Dios? Bastante es con que llegue a tocarlo, en el caso de que el ojo esté limpio. Con todo, si llega a tocarlo, lo toca con cierto tacto incorpóreo y espiritual, pero no lo abarca; y esto en el caso de que esté limpio. Y el hombre se hace bienaventurado si logra tocar con el corazón al ser que permanece siempre bienaventurado [...] Dios no es más porque lo conozcan; quien le conoce, en cambio, es más al conocerle" 102 .

En esta misma línea y atendiendo a un caso de probable intertextualidad ${ }^{103}$, Tomás invoca los grados de visión en su Comentario al Evangelio según San Juan (3, 1-6). Señala que la visión es un acto de vida, de modo que los grados de visión se diversifican de acuerdo con los tipos de vida. Hay cierta vida carnal, a cuyo género corresponde una visión o conocimiento carnales. Hay, empero, una vida espiritual, por la cual el hombre es conformado a Dios y a los santos espíritus. Lo espiritual no puede ser visto según lo carnal, porque si lo espiritual es vida y lo carnal es muerte, se puede concluir con Agustín que "el percibir según la carne conlleva la muerte" 104 .

Ello es que la propia vida influye en el modo de captar la realidad espiritual, en la medida en que lo recibido está contenido según el modo de ser del continente. A causa de esto, es menester orientar la propia mirada para poder ver como es debido. Tomás de Aquino supone el ingreso en lo interior como condición indispensable para ver con rectitud, a fin de que cuanto más se avance, más se progrese en la claridad visual ${ }^{105}$.

102 Sermo 117, 3, 5: "Ecce de corporibus dicimus subiacentibus oculis nostris, non illa possunt comprehendere aspectu; quis ergo oculus cordis comprehendit Deum? Sufficit ut attingat, si purus est oculus. Si autem attingit, tactu quodam attingit incorporeo et spiritali, non tamen comprehendit; et hoc, si purus est. Et homo fit beatus contingendo corde illud quod semper beatum manet [...] Deus non crescit ex cognitore, sed cognitor ex cognitione Dei”.

${ }_{103}$ Cf. supra n. 93.

104 En. in ps. 150, 8: "[...] sapere secundum carnem, mors est".

105 Cf. Super evangelium S. Ioannis lectura, cura P. Raphaelis CAI, editio V revisa (Marietti, Taurini-Romae 1952) lectio 1, 432-434. En español existe la trad. de P. 
Dice el Aquinate que así como uno no tiene ojos corpóreos si no ha nacido a la vida sensible, tampoco puede tener una percepción espiritual si no ha sido regenerado ${ }^{106}$. Por tanto, según la triple regeneración hay un triple modo de visión. El Aquinate sostiene que los antiguos padres accedieron a una regeneración espiritual, si bien imperfecta y figurada, por eso veían los misterios del Reino de Dios pero solo en esperanza. Por otra parte, la regeneración espiritual se ha manifestado en la Nueva Ley; sin embargo, continúa siendo incompleta porque el hombre se renueva interiormente mediante la gracia y no exteriormente mediante la incorrupción. Se ven los misterios pero como en enigma. Solo en la Patria la regeneración es perfecta. Allí será posible ver a Dios cara a cara, al efectuarse una renovación tanto interior como exterior ${ }^{107}$.

Esta disposición es puesta a favor del entendimiento creado para la visión de la esencia divina, por ser ella misma la que produce la forma inteligible en el alma como una iluminación del entendimiento que aumenta su capacidad intelectiva. En síntesis, la bienaventuranza para Tomás consiste: (a) en la visión como conocimiento perfecto del fin inteligible; (b) en su comprehensión, porque supone la presencia luminosa y transparente de ese fin y (c) en la delectación o fruición, que conlleva el reposo del amante en el objeto amado ${ }^{108}$, al punto tal que Tomás recalca la delectación concomitante al acto beatífico, como el gozo propio de la voluntad racional en virtud del bien alcanzado ${ }^{109}$. De allí que el enfoque de la bienaventuranza propiciado por el Aquinate radique en la libertad espiritual, por cuyo medio el hombre se une a Dios en una perfección susceptible de ser calificada de ejemplar ${ }^{110}$. Esta unión alcanza su punto culminante cuando el ser humano ordena su acto en vista del conoci-

Cavallero, Comentario al Evangelio según San Juan (Ágape Libros, Buenos Aires 2005) t. 2.

106 Agustín habla de una doble generación en su comentario al Salmo 134, 21: "Generatio ista et generatio altera".

107 Tomás de Aquino, Comentario..., 88-89.

108 Cf. S. Th. I-II, q. 4, a. 3, sol.: "Et ideo necesse est ad beatitudinem ista tria concurrere, scilicet visionem, quae est cognitio perfecta intelligibilis finis; comprehensionem, quae importat praesentiam finis; delectationem, vel fruitionem, quae importat quietationem rei amantis in amato".

109 Cf. S. Th. I-II, q. 4, a. 1, sol.

110 Cf. G. Lafont, Estructuras y método en la Suma Teológica de Santo Tomás de Aquino, trad., pról. y notas de N. López Martínez (Ed. Rialp, Madrid 1964) 181-196, 272-268. 
miento y el amor divinos ${ }^{111}$. Por ello, la comprehensión no constituye una operación diferente de la visión, sino una relación particular con la felicidad alcanzada, es decir, al ser vista la esencia divina, y en la medida en que está presente donando a la vez la visión de su gloria al alma bienaventurada, se comporta qua objeto comprehensivo y amado en cuanto $\operatorname{tal}^{112}$.

No obstante todos estos argumentos, un tratamiento minucioso de los aportes tomasianos acerca de la materia en curso, así como de su vínculo directo con la doctrina agustiniana, exceden los propósitos de las presentes líneas. Queda abierta la posibilidad para ser examinados con el debido cuidado en una investigación futura.

\section{CONSIDERACIONES FINALES}

Conforme con los aspectos formulados a lo largo de este trabajo, se puede concluir que si el cuerpo sensible es de condición visible y el hombre interior, invisible; entonces, será siempre mucho mejor ver con la mente que con el cuerpo. Con aquella, son vistos objetos que no están contenidos en lugares, ni separados entre sí por distancias locales. Para ser consciente de la mirada interior, el propósito agustiniano estriba en apartar con vigilancia todas las imágenes que el hombre exterior haya introducido mediante el sentido sensible. Si este ejercicio se torna arduo, ello responde a que una turba de fantasmas similares a los cuerpos ha invadido el ojo interior.

De esto último, se infiere el compromiso personal que asume este tipo de elaboraciones en torno a la visión espiritual ${ }^{113}$. Se ha intentado mostrar que la semejanza bienaventurada es el fin al que apunta el comportamiento del hombre interior. En consecuencia, sería sencillamente fatuo bosquejar un esquema metódico sobre la visión suprema, puesto que si alguien adolece de su cultivo, no podrá comprenderla por muchas

111 Cf. S. Th. I-II, q. 3, a. 8, s. c. R. Crespo, "El acto humano: Aristóteles y Tomás de Aquino", en Sapientia 51/199 (1996) 7-11.

112 Cf. S. Th. I-II, q. 4, a. 3, ad 3; II-II, q. 27, a. 6, sol.

113 Cf. M. Thomaz Ramos, A Ideia de Estado na Doutrina Ético-Politica de Santo Agostinho (Letra \& Vida, Porto Alegre $\left.{ }^{2} 2015\right) 1^{a}$ parte, passim. 
instrucciones que reciba. Claro que para llegar a gozar de los bienes que entraña, se requiere vaciar el corazón de los malos deseos ${ }^{114}$.

En resumidas cuentas, en la visión espiritual no prima tanto el carácter transitivo del mirar cuanto el proceder reflexivo del conocer. Este acto no implica percibir algo más sino, antes bien, la recepción primera de lo que se otorga al ver, a fin de columbrar que ya desde antes uno mismo era contemplado por Dios ${ }^{115}$. Una vez que ello se torna evidente, se advierte entonces las graves limitaciones del propio potencial sensitivo para abarcar por completo el objeto verdadero de visión ${ }^{116}$. En este punto, la experiencia de lo allende transmuta para asumir los visos de un retorno hacia el Creador, cumpliendo así el itinerario agustiniano que va de lo exterior a lo interior y de lo interior a lo superior ${ }^{117}$.

114 Cf. En. in ps. 136, 10: "oportet ut exinaniaris quo plenus es, ut possis impleri quo inanis es".

115 Cf. De Trinitate IX, 1, 1: "Quisquis autem diligit Deum, hic cognitus est ab illo".

116 Cf. DcD XXII, 30, 1-2.

117 Cf. Ó. Velásquez, "La creación como retorno al Creador en Confessiones XI-XIII", en línea: http://diadokhe.olea.biz/wp-content/uploads/2016/03/creacion.pdf, fecha de consulta: 01.09.2017. 